\title{
Rock slope stability evaluation in static and seismic conditions for left bank of Jinsha River Bridge along Lijiang-Xamgyi'nyilha railway, China
}

\author{
Zhiming $\mathrm{ZHAO}^{1 *}$, Guang WU${ }^{1}$, Esamaldeen $\mathrm{ALI}^{2}$, Xihua $\mathrm{WANG}^{3}$, Chuan $\mathrm{KOU}^{4}$ \\ 1. School of Geosciences and Environmental Engineering, Southwest Jiaotong University, Chengdu 610031, China \\ 2. Faculty of Petroleum and Minerals, Al Neelain University, Khartoum 11121, Sudan \\ 3. School of Resources and Environment, Southwest Petroleum University, Chengdu 610500, China \\ 4. China Railway Eryuan Engineering Group Co. Ltd., Chengdu 610031, China
}

\begin{abstract}
Jinsha River Bridge is located along the Lijiang-Xamgyi'nyilha railway on the southeastern Tibet plateau; it is an area with a high prevalence of earthquakes. The bridge abutments were designed to be constructed in river bank slopes, where rocks are controlled by two sets of joint planes that significantly influence the stability of the left bank slope. According to the engineering-geological conditions and the characteristics of discontinuities, strength properties of the rock mass were obtained based on Barton model and direct shear test. Numerical analyses were performed using FLAC $^{3 \mathrm{D}}$ software to examine the slope's response to seismic loading. Then in order to evaluate the damage trends of the rock mass under the different loading conditions, a calculation model based on the geological parameters and slope stability was simulated and analyzed using the discrete element numerical simulation program UDEC (Universal Distinct Element Code), and the effect of degradation of discontinuities on the slope stability was investigated. The results show that the destruction of rock mass under the gravity, bridge foundation, and seismic load are mainly concentrated within $30 \mathrm{~m}$ depth of slope, and the slope under loading may slide along joint planes. In addition, the dynamic analysis by amplification of the input loading indicates that instability occurs to the bank slope at a height of about $200 \mathrm{~m}$, and rock blocks will fail under seismic load. Therefore, to prevent the slope from deformation under the engineering loading and strong earthquakes, the bridge foundation should be strengthened.
\end{abstract}

Key words: strength properties; joints planes; slope stability; discrete element method; dynamic analysis

(C) 2012 JMT. All rights reserved.

\section{Introduction}

$\mathrm{L}$ ijiang-Xamgyi'nyilha railway is located in a highintensity seismic region on the southeastern Tibet plateau at the middle part of the Hengduan mountain range, China (Fig. 1). The railway passes over the deep Jinsha River with high bank slopes and complex geological conditions. A bridge with high abutments is designed to cross the river at Tiger Leaping Gorge along the Jinsha River, and the bridge abutments need to be built on steep slope.

Generally, in the field of rock engineering, it has been recognized that geological structures significantly influence the response of rock masses to loadings and excavation [1]. Slope stability is affected by the strength

Received May 21, 2012; revision accepted Jun. 4, 2012

${ }^{*}$ Corresponding author. Tel.:+86-28-87634039

E-mail: zmzhao@swjtu.cn (Z.M. ZHAO)

(C) 2012 JMT. All rights reserved

doi: 10.3969/j.issn.2095-087X.2012.03.001 and deformation properties of intact rocks, geometry and distribution of discontinuities throughout a rock mass [2]. Failures usually initiate and follow preexisting discontinuities rather than break through intact rocks [3]. Thus, it is the nature of the discontinuities (joints, fractures, bedding planes and faults) and not of the intact rock that governs the mechanical behavior of the rock mass. Ensuring the stability of rock slopes requires analyzing the structural fabric of the site to determine if the mechanical parameters of the discontinuities could result in instability of the slope under consideration. Traditionally, analytical calculations of potential instability are carried out by means of limit equilibrium models; more recently, however, numerical models are dominantly in use [4-7]. Discontinuous numerical methods such as the discrete element method (DEM) has been successfully applied to slope stability analysis and are now in routine use in civil and mining engineering, particularly in the area of disaster prevention [8-10]. The advantage of these numerical models over the limit 


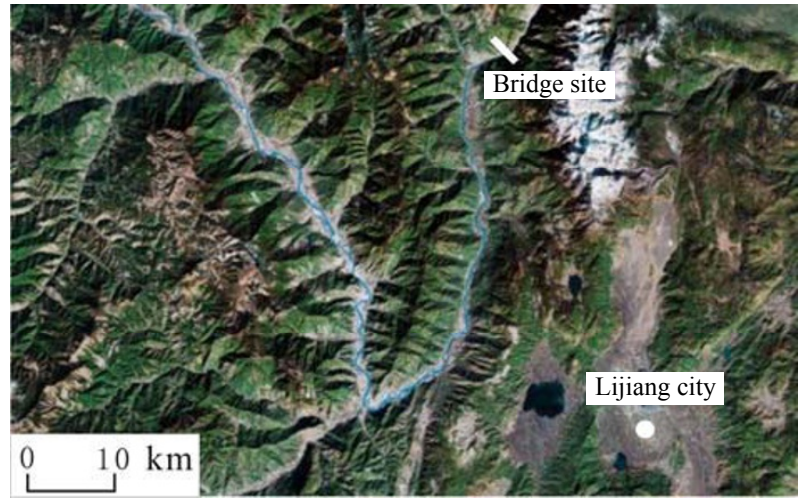

Fig. 1 Location map of the proposed bridge site

equilibrium models is that they can be used to model progressive failure and displacement rather than a simple factor of safety [11]. Moreover, engineers have intelligent interpretations of the DEM simulation results, which is helpful in developing more confidence and economic designs. Hence, rocks with potential failure must be restrained in some way.

Up to now, it is difficult to obtain the accurate strength parameters of discontinuities in geotechnical engineering. These parameters are usually obtained by the standard code or experiments. Both of the two methods had been used for Jinsha River Bridge site. In order to obtain a safe design for the Jinsha River Bridge, we carried out an engineering geological investigation of its left bank slope, and made a probabilistic analysis of the slope stability under different loading conditions (static and seismic loads). The study involves field and laboratory testing of strength properties of discontinuity surfaces and subsequent stability assessment based on DEM numerical analysis. Some important findings are obtained from comparison of the experimental data with the standard values in the code.

\section{Characteristics of the bridge site}

At the bridge site, the Jinsha River flows in an NNE direction with a 100-200 m width. Morphologically, the slope of the river banks is very steep, especially where the vegetation is not developed. As a result, collapse and rock slides toward the valley occur frequently. There is an unloading fracture with a length of about $60 \mathrm{~m}$ parallel to the river direction (Fig. 2).

From the lithological point of view, the exposed Triassic metamorphic rocks mainly consist of moderately thick layers of slate overlain by schistose basalt. A representative geological cross section of the rock slope was obtained as illustrated in Fig. 3. The rocks are intensively schistose, striking $\mathrm{N} 18^{\circ} \mathrm{W}$ with a dip angle $61^{\circ}$ to the NE. The foliation planes are slightly weathered with no rust dye and mineral alteration (carbontization,

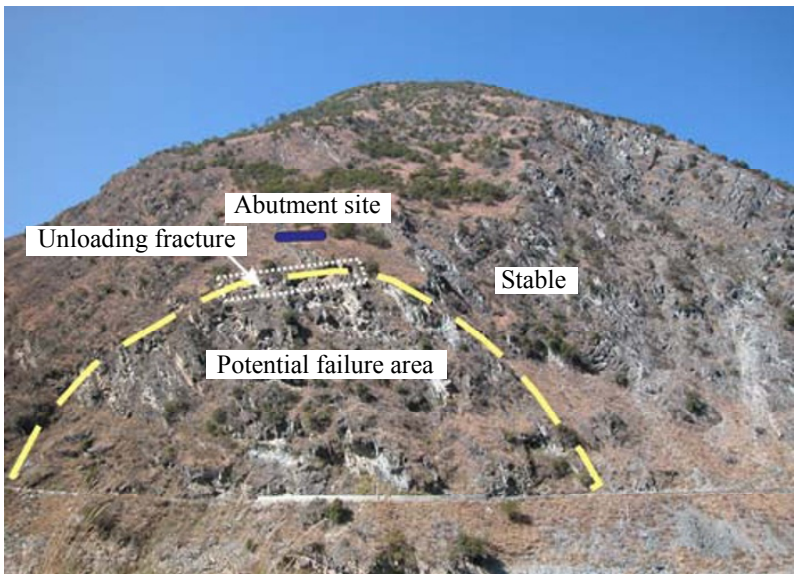

Fig. 2 Panorama view of the rock slope

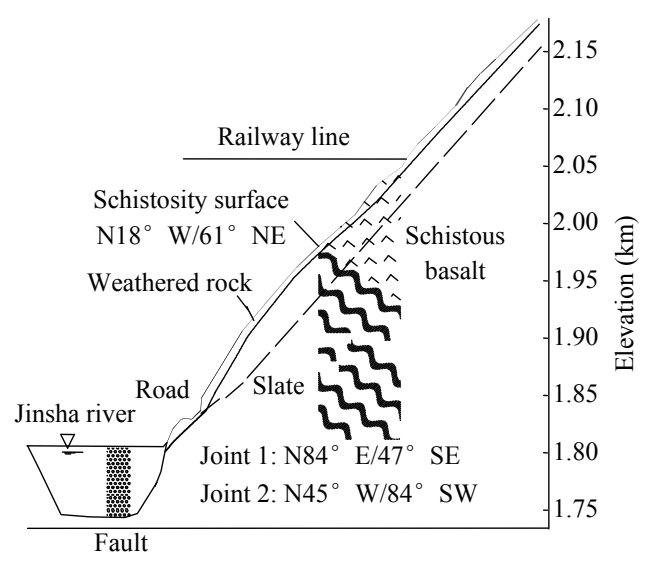

Fig. 3 Stratigraphical cross section of the rock slope

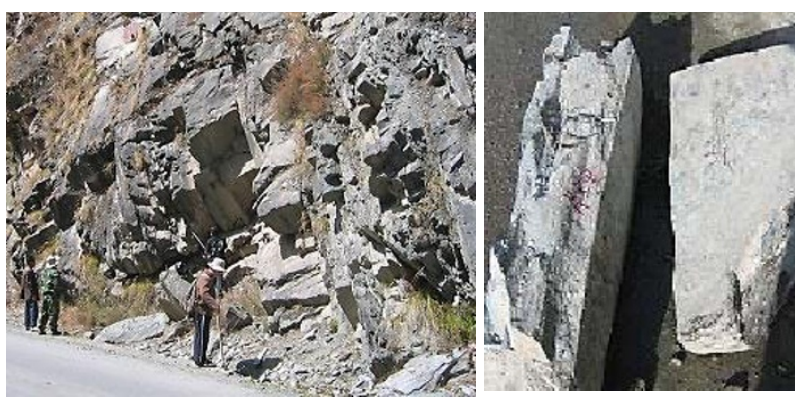

Fig. 4 Side and close-up view of rock slope showing fracturing and dimension of the rock mass

chloritization, epidotization, etc) along the schistosity planes, in addition to the absence of filling material.

The rocks are characterized by two distinct major joint sets: a) trending $\mathrm{N} 84^{\circ} \mathrm{E}$ dipping $47^{\circ}$ to the SE, and b) trending $N 45^{\circ} \mathrm{E}$ with dip angle $84^{\circ}$ to the SE. Due to the joints intersecting, the rock mass separated into small blocks ranging from $30 \mathrm{~cm}$ to $80 \mathrm{~cm}$ thick (Fig. 4).

Based on the site survey [12], the high unloading fractured zone is about $10.5 \mathrm{~m}$ deep and the moderately fractured unloading zone is about $10 \mathrm{~m}$ deep (measured from the roadside laterally). In a normal case, tendency, dip 
and length of the joints have a close relation with the mechanical parameters of rock mass and slope stability [13].

\section{Estimation of the shear strength}

At the bridge site, the rocks are highly schistose and controlled by two joint sets. The hardness, roughness, depth of weathering, water, and type of filling materials are the factors influencing the shear strength of the discontinuities [14]. To obtain shear strength properties of the discontinuity surfaces, some in-situ and laboratory tests were carried out. However, the high cost of the insitu shear tests, together with the difficulty of interpreting the results have resulted in a decline in the use of large scale tests [15]. Since the 1960s, many researchers have explored the methods for estimating the strength of rock discontinuity through mechanical characteristics of the rock mass. Among them, the empirical approach model proposed by Barton [16] found wide applications in engineering practices:

$$
\tau=\sigma \cdot \tan \left[\phi_{\mathrm{b}}+J R C \cdot \lg \left(\frac{J C S}{\sigma}\right)\right],
$$

where $J R C$ is joint roughness coefficient; JCS is joint wall compressive strength, in $\mathrm{MPa} ; \varphi_{\mathrm{b}}$ is basic friction angle; and $\sigma$ is effective normal stress on joint surface, in MPa.

The amplitude of $J R C$ was estimated by visually comparing the appearance of the joint surface with Barton and Choubey standard profile [17] (Fig. 5), where the value of JCS was calculated by the following equation [18]:

$$
\lg (J C S)=0.00088 \gamma_{\mathrm{d}} R_{e}+1.01,
$$

where $\gamma_{\mathrm{d}}$ is bulk volume weight, in $\mathrm{kN} / \mathrm{m}^{3}$; and $R_{e}$ is Schmidt rebound hammer hardness value.

The value of friction angle $\varphi$ and cohesion $c$ can be calculated according to the model as shown in Fig. 6:

$$
\begin{aligned}
& \varphi=\arctan \left(\frac{\partial \tau}{\partial \sigma}\right), \\
& c=\tau-\sigma \tan (\varphi) \\
& \frac{\partial \tau}{\partial \sigma}=\tan \left(\varphi_{\mathrm{b}}+J R C \cdot \lg \frac{J C S}{\sigma}\right)- \\
& \frac{\pi \cdot J R C}{180 \ln 10}\left[\tan ^{2}\left(\varphi_{\mathrm{b}}+J R C \cdot \lg \frac{J C S}{\sigma}\right)+1\right] .
\end{aligned}
$$

The results obtained from field measurements show that the minimum joint space is about $20 \mathrm{~mm}$, and the maximum is more than $1.0 \mathrm{~m}$. The $J R C$ for the joint surface and foliation plane (schistosity) are in the ranges of 3-5 $\mathrm{mm}$ and 1-2 $\mathrm{mm}$, respectively. The two structural surfaces are characterized by intimate contact with no fill- ing materials. According to the bridge design data [12], the added maximum stress (bridge load) of the main base is $1.5 \mathrm{MPa}$, and the maximum normal stress is $5 \mathrm{MPa}$ (Table 1). The basic friction angle of schistose planes and joint surfaces is $32^{\circ}$ and $28^{\circ}$, respectively [19].

To obtain the friction angle $(\varphi)$ and cohesion $(c)$ of the structural planes precisely, samples were chosen care-

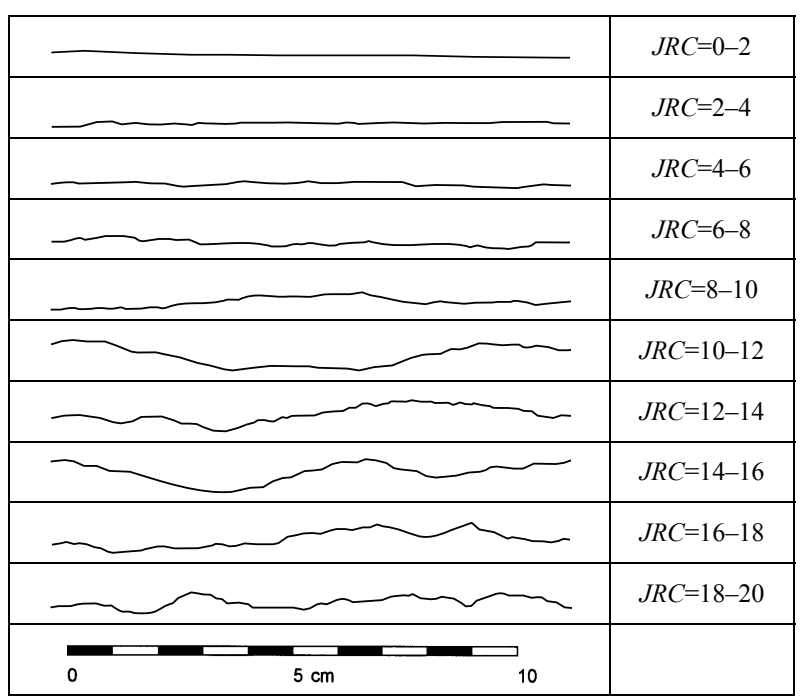

Fig. 5 Marked range of JRC value of discontinuity surface [17]

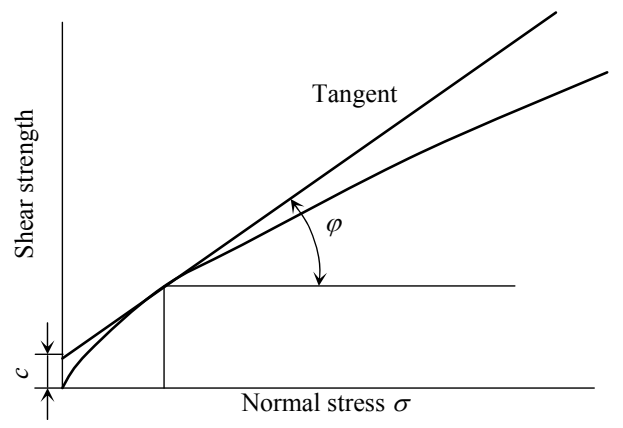

Fig. 6 The calculation model of shear strength parameters ( $c$ and $\varphi$ ) of the discontinuity

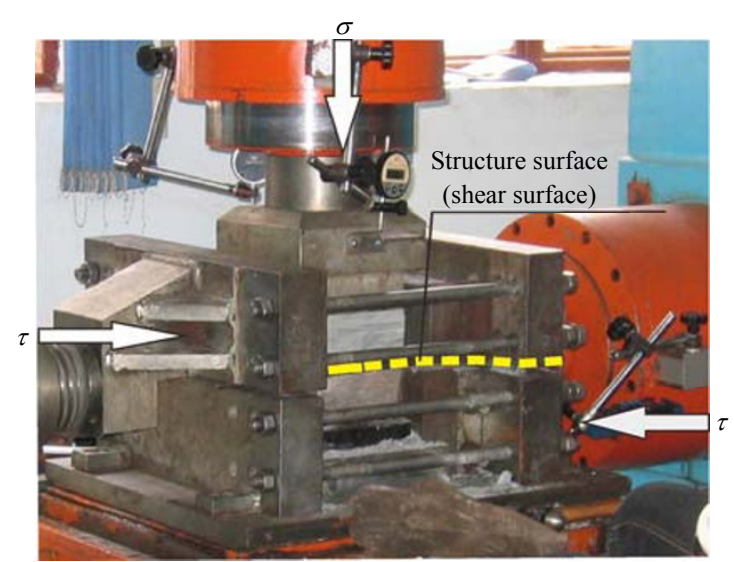

Fig. 7 Direct shear test apparatus for discontinuities 
fully for laboratory test. The test was done by direct shear test apparatus (Fig. 7). The test specimens are cubic in shape with length not less than $150 \mathrm{~mm}$ (Figs. 7 and 8 ). In the test, the shear displacement was $1.0 \mathrm{~cm}$, the maximum normal stress was scheduled to be $10 \mathrm{MPa}$

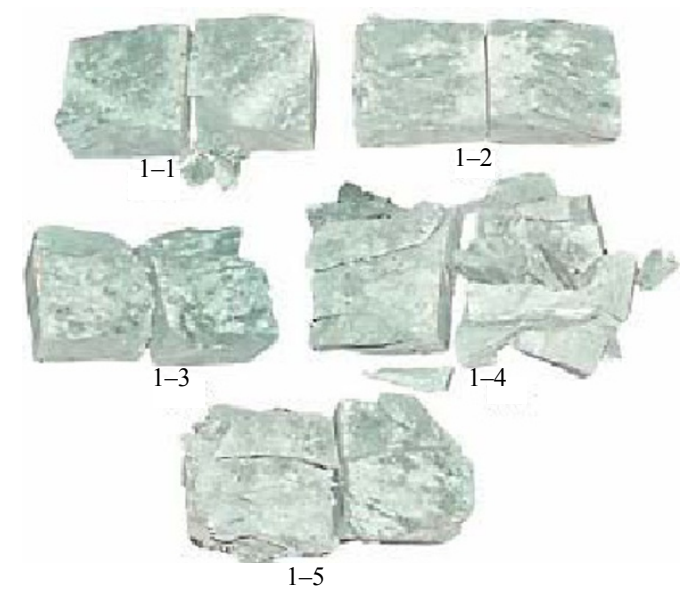

Fig. 8 Morphologies of specimens after laboratory experiment

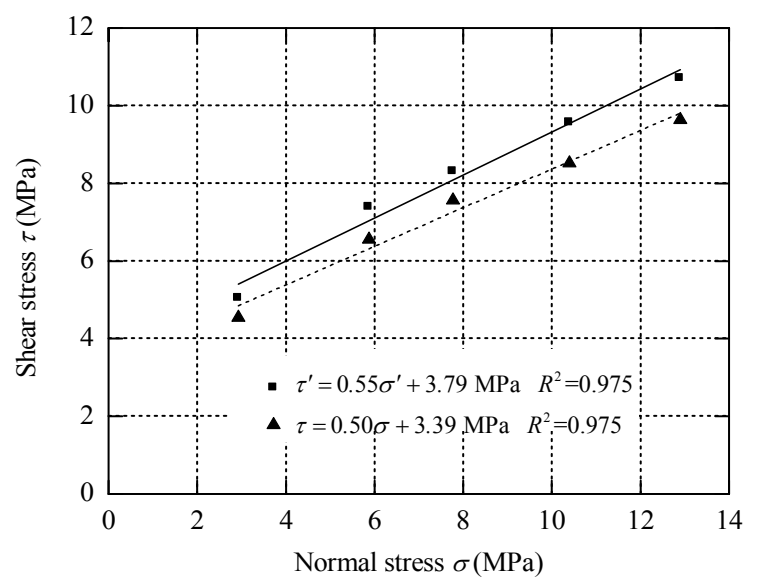

(a) Schistose plane and adjusted appropriately according to the specimens and deformation conditions). Based on the peak value, the critical shear strength parameters $\left(\varphi^{\prime}, c^{\prime}\right)$ are calculated with least square method [20] (see Fig. 9, where $\tau^{\prime}$ is the critical shear strength). The results are shown in Table 2.

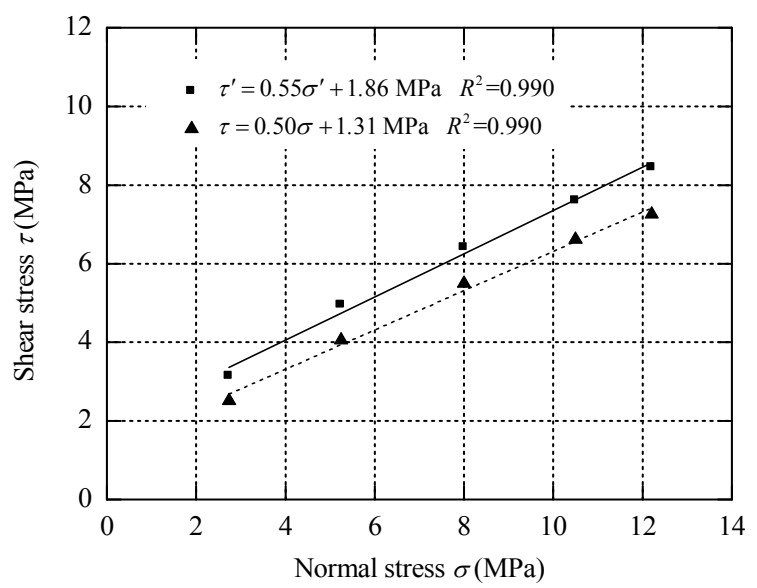

(b) Joint No. 1

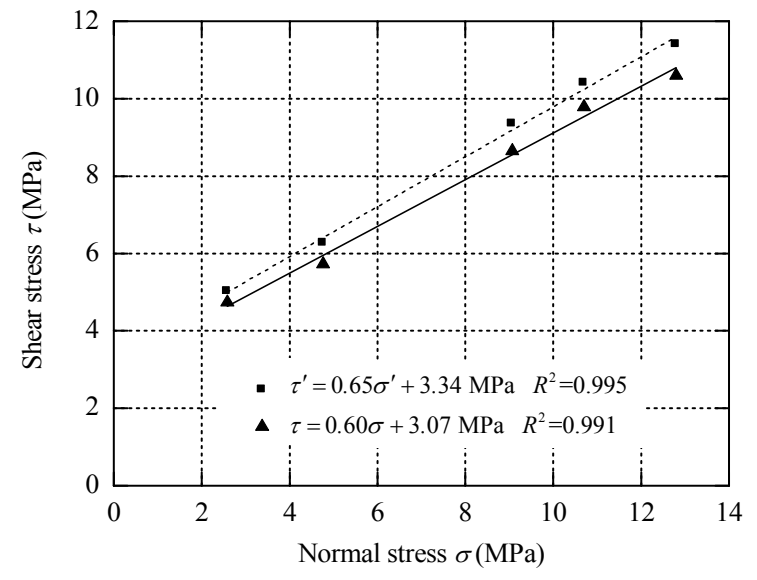

(c) Joint No. 2

Fig. 9 Shear strength-normal stress diagrams

Table 1 Shear strength properties of structural planes calculated based on Barton model $(\sigma=5 \mathrm{MPa})$

\begin{tabular}{lcccccccc}
\hline Structural plane & Altitude & $R_{e}$ & $\varphi_{\mathrm{b}}\left({ }^{\circ}\right)$ & $J R C$ & $J C S(\mathrm{MPa})$ & $\tau(\mathrm{MPa})$ & $\varphi\left({ }^{\circ}\right)$ & $c(\mathrm{MPa})$ \\
\hline Joint 1 & N84E/47E & 15.7 & 28 & $2-4$ & 11.04 & 1.71 & 28.38 & 0.090 \\
Joint 2 & N45E/84E & 20.2 & 28 & $4-6$ & 11.29 & 1.75 & 28.53 & 0.122 \\
Schistose & N18W/61NE & 24 & 32 & $2-4$ & 11.49 & 2.00 & 32.43 & 0.099 \\
\hline
\end{tabular}

Table 2 Shear strength parameters of the structural planes

\begin{tabular}{lccccc}
\hline Structural plane & Maximum normal stress $(\mathrm{MPa})$ & $\varphi^{\prime}\left({ }^{\circ}\right)$ & $c^{\prime}(\mathrm{MPa})$ & $\varphi\left(^{\circ}\right)$ & $c(\mathrm{MPa})$ \\
\hline Joint 1 & 12.9 & 28.8 & 3.79 & 28.8 & 3.39 \\
Joint 2 & 12.2 & 28.8 & 1.86 & 26.6 & 1.31 \\
Schistose & 12.8 & 28.8 & 3.34 & 32.2 & 3.07 \\
\hline
\end{tabular}




\section{Rock slope's response to seismic dy- namic loading}

Rockslides of the natural slopes usually occur under strong earthquakes. In most cases, such sliding is governed by combination of geological conditions and earthquake loading. During an earthquake, rock mass failure occurs when the shear resistance of the controlling joint surface(s) is exceeded by shaking-induced inertial forces [21]. As mentioned in the preceding section, the area under investigation is located in highintensity seismic environment. Therefore, it is important to analyze the rock mass slope. To date, various numerical models of seismically induced failure have been proposed (e.g., [22]), and the simulation results produced by these models are rather accurate for estimation of the damage induced by earthquakes.

To analyze the stability of the left bank slope of the bridge site, a 3D numerical simulation analysis using FLAC $^{3 \mathrm{D}}$ software [23] has been used. The earthquakes spectrum reported by Ref. [3] is used here for dynamic analysis. Basic parameters of slope analysis are as follows: damping ratio is 0.05 , the peak ground acceleration (PGA) is $0.20 \mathrm{~g}$, and the time history of the ground surface acceleration is adopted as the input ground motion, as shown in Fig. 10. According to the seismic data and mechanical parameters of the rock mass (Table 3 ), the base of the slope model is set with a static boundary and the flanks are set with a free boundary (Fig. 11).

The main factors affecting the amplitude of ground shaking are the slope inclination and the vertical distance from the crest of the slope [24], in addition to earthquakes frequency content and the direction of seismic waves, which are also important factors affecting topographic amplification [8].

In order to detect the amplification and attenuation states in the numerical model under seismic loading, the acceleration response is monitored at the top and bottom of the slope model (Figs. 12 and 13).

To illustrate the status and structural behaviour of the rock slope, a 3D model was constructed, which shows the distribution characteristics of maximum shear stress of each block under the seismic load, and the areas of tensile stress concentration (Fig. 14).

Table 3 Mechanical parameters of rock mass

\begin{tabular}{lccccc}
\hline Rock type & $\begin{array}{c}\text { Unit } \\
\text { weight } \\
\left(\mathrm{kN} / \mathrm{m}^{3}\right)\end{array}$ & $\begin{array}{c}E \\
(\mathrm{GPa})\end{array}$ & $\begin{array}{c}\text { Poisson's } \\
\text { ratio }\end{array}$ & $\begin{array}{c}c \\
(\mathrm{MPa})\end{array}$ & $\begin{array}{c}\varphi \\
\left({ }^{\circ}\right)\end{array}$ \\
\hline Slate & 26 & 26 & 0.25 & 3 & 35 \\
$\begin{array}{l}\text { Schistosity } \\
\text { basalt }\end{array}$ & 27 & 27 & 0.16 & 10 & 35 \\
\hline
\end{tabular}

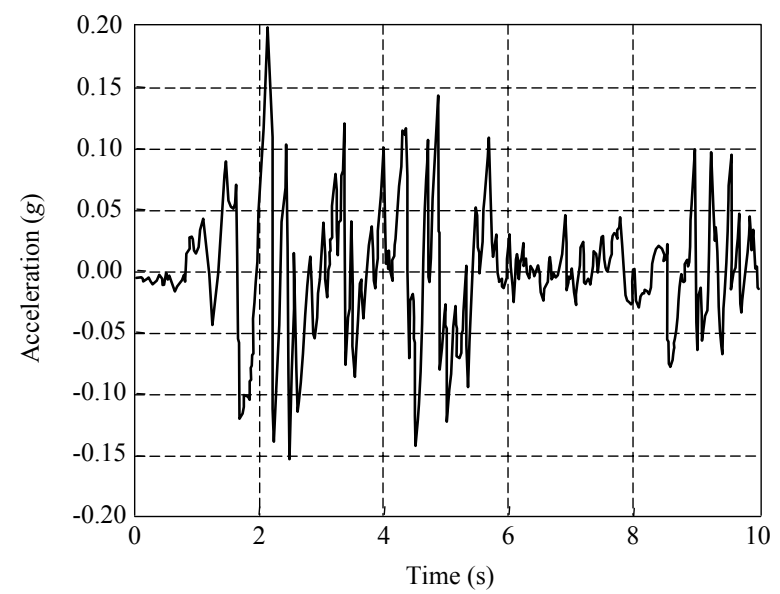

Fig. 10 Time-history curve of the ground surface acceleration used in the model

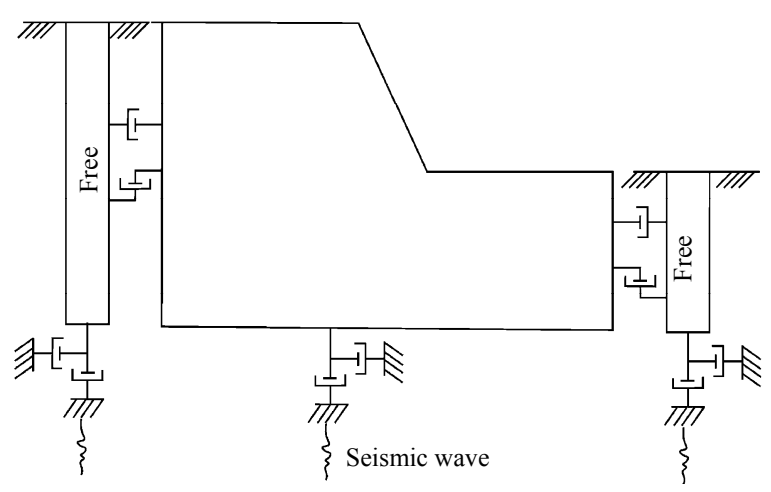

Fig. 11 Boundary conditions for the dynamic analyses

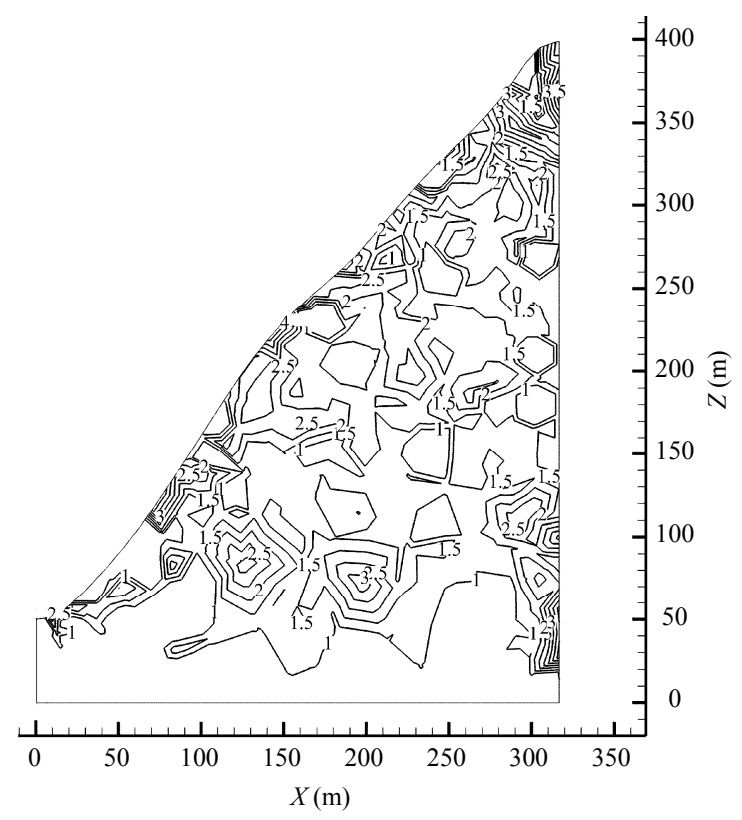

Fig. 12 The acceleration amplification coefficient in the $x$ direction 


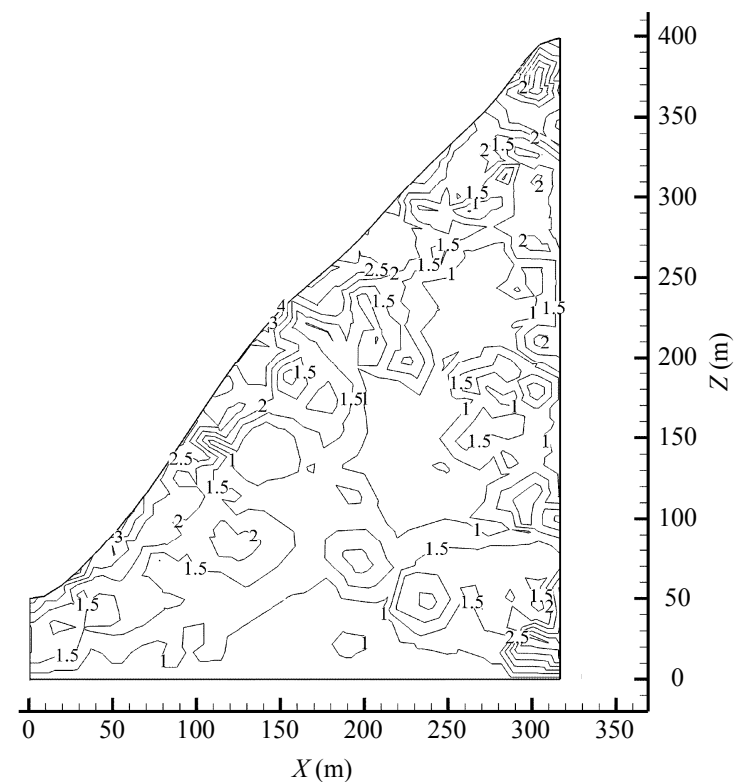

Fig. 13 The velocity amplification coefficient in the $x$ direction

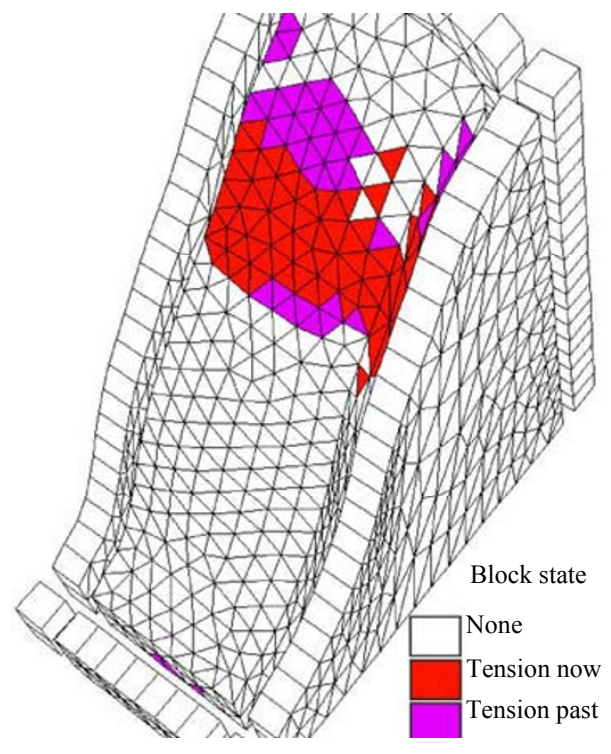

Fig. 14 The status of rock block

\section{DEM analysis}

Discontinuous numerical modeling is thought to be more appropriate to simulate a rock slope with joint sets controlling the failure mechanism [4]. Therefore, in order to assess the damage trend of the rock mass under gravity, bridge foundation, and seismic load, a calculation model based on the geological model and slope stability is built using discrete element methods (DEM). The response of the jointed rock slope subjected to static and dynamic loading is simulated using (UDEC) software [25].

The UDEC can take the mechanical parameters of discontinuities into account to analyze the slope and the dis- placement. The mechanical parameters of the intact rock and discontinuities are shown in Tables 2 and 3, respectively. The boundary conditions are assumed along the lateral sides of the model such that no displacement is allowed in the $x$ direction. At the base of the numerical model, the boundary is fixed such that no displacement is allowed in the $y$ direction (Fig. 15).

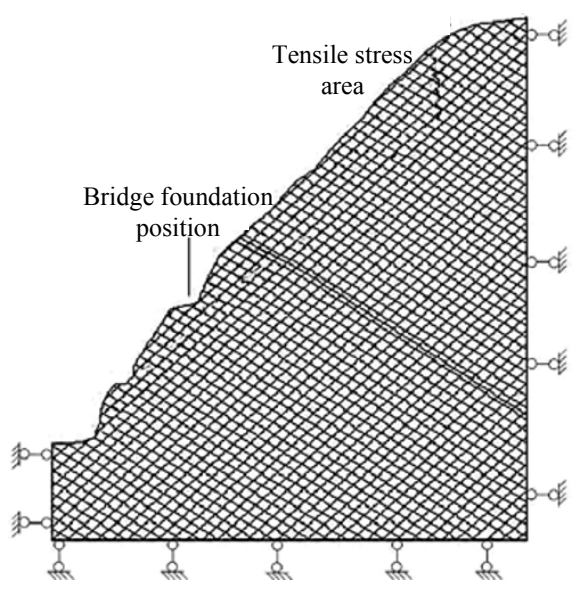

(a) Under gravity

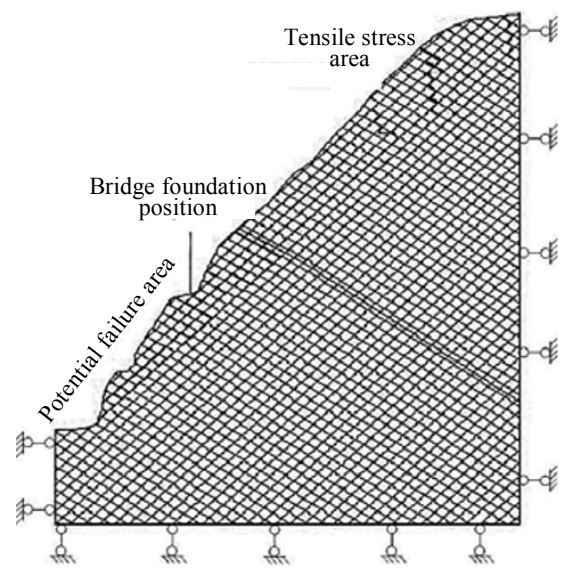

(b) Under bridge loading

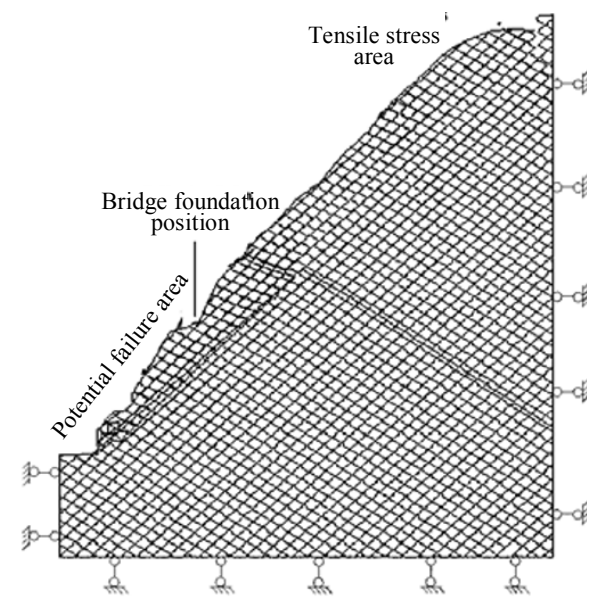

(c) Under both static and seismic loading

Fig. 15 Characteristic failure of slope under different loading 


\section{Discussions}

(1) From the laboratory experimental results (Table 2 ), the surface planes of group 3 (schistose plane) rock specimens are cemented partially, and the results can be used to represent the shear strength of partially cemented slates; while group 1 and group 2 represent the shear strength of the unloading-formed and uncemented joint surface. According to the standard code of building slope engineering [19], the values of shear strength parameters of general structural planes is $27-35^{\circ}$ for internal friction angle and $0.13-0.09 \mathrm{MPa}$ for cohesion. Comparing the experimentally obtained data with the standard values, we can see that the friction angle values basically agree with those in the code, and the difference is less than $4 \%$.

The laboratory tested value of cohesion $(c)$ is obviously high, because during the laboratory test, the value is affected largely by test conditions and specimen state (size, shape, and sampling technique).

With the application of the larger normal stress in the test, shearing failure occurs in the bulge part of the structure surface. Therefore, it is concluded that the mode of JRC-JCS model is effective, while the cohesion of the shear test should be reduced according to the practical situation. For the clean structure surface without fillings, the value of cohesion should be set to $0 \mathrm{MPa}$.

(2) From the results of the dynamic analysis of rock the slope, the isolines of acceleration are parallel to the slope surface as shown in Fig. 12. The amplification coefficient increases from inside to outside, and reaches a maximum at the slope surface. From the toe of the slope, the acceleration at the surface increases in a fluctuating manner with slope height. It reaches a maximum at the height of about $120-200 \mathrm{~m}$ of the slope (4 times more than that at the toe). Similar distribution characteristics are found in the amplification coefficient of $x$-velocity (Fig. 13) that reaches a maximum at the height of approximately $200 \mathrm{~m}$ (4 times more than that at the toe). Thus, from the numerical analyses, it is clear that the rock mass of the bank slope separated by joint discontinuities is unstable at the height of about $200 \mathrm{~m}$ and will undergo failure under seismic load (Fig. 14).

(3) According to the DEM analysis, the failure of the rock mass under gravity, bridge foundation, and seismic load are mainly concentrated at $30 \mathrm{~m}$ depth. The natural slope and the slope under loading (bridge foundation and seismic load) may slip along joint planes, where the whole slope is stable.

\section{Conclusions}

Numerical modeling analyses were performed using DEM to predict the stability of the jointed rock slope of the left bank slope of Jinsha River Bridge site. In order to model static and dynamic deformation of jointed rock, attention should be paid to determine as accurately as possible the mechanical properties of the rock mass and the geometry of the rock structure. The study has obtained a better insight into the deformation condition of the blocks formed by rock discontinuities. The main conclusions of the study are summarized as follows:

(1) The JRC-JCS model of Barton is an appropriate method for the determination of shear strength parameters of structure planes.

(2) The results of the laboratory test of joints showed that the friction angle is similar to the data obtained by the Barton model or technical code for building slope engineering. However, the value of cohesion $(c)$ is clearly high, because during the laboratory testing, the value is affected largely by test conditions and specimen state (size, shape and sampling technique). Its value should be reduced based on the circumstances.

(3) Dynamic analysis of the slope shows that the amplification of the input loading resulted in an instability of slope at a height of about $200 \mathrm{~m}$ and rock blocks will undergo a failure under seismic load.

(4) DEM analysis shows that the destruction of rock mass under gravity and bridge loading are mainly concentrated within $30 \mathrm{~m}$ depth from slope surface.

(5) The whole slope is stable, but rockslide is easy to occur along the joint planes under engineering loading and strong earthquakes.

\section{Acknowledgements}

This research was financed by China Railway Eryuan Engineering Group CO. LTD (2009-LiXiang Railway-13) and the Fundamental Research for the Central Universities (SWJTU09BR033).

\section{References}

[1] R.E. Goodman, Introduction to Rock Mechanics, 2nd ed., Toronto: John Wiley \& Sons, 1989.

[2] C. Duncan, W. Christopher, Rock Slope Engineering, 4th ed., London: Taylor \& Francis, 2004.

[3] E. Hoek, J.W. Bray, Rock Slope Engineering, 3rd ed., London: Institution of Mining and Metallurgy, 1981.

[4] E. Eberhard, Rock slope stability analysis-utilization of advanced numerical Techniques, Engineering Geology, 2003, 71: 213-226.

[5] D. Stead, E. Eberhardt, Developments in the characterization of complex rock slope deformation and failure using numerical modeling techniques, Engineering $\mathrm{Ge}$ ology, 2006, 83: 217-235.

[6] R.E. Hammah, T.E. Yacoub, B. Corkum, et al., Analysis of blocky rock slopes with finite element shear 
strength reduction analysis, In: Proceedings of the $1 s t$ Canada-U.S. Rock Mechanics Symposium, Vancouver, Canada, 2007: 329-334.

[7] J. Kozicky, F.V. Donze, A new open-source software developed for numerical simulations using discrete modeling methods, Computational Methods in Applied Mechanics and Engineering, 2008, 197: 4429-4443.

[8] O. Mavrouli, J. Corominas, J. Wartman, Methodology to evaluate rock slope stability under seismic conditions at Sola de Santa Coloma, Andorra, Nat. Hazards Earth Syst. Sci., 2009, 9: 1763-1773.

[9] C.L. Liu, S.W. Qi, L.Q. Tong, et al., Stability analysis of slope under earthquake with FLAC3D, Chinese Journal of Rock Mechanics and Engineering, 2004, 23(16): 2730-2733 (in Chinese).

[10] C.H. Zhang, O.A. Pekau, F. Jin, et al., Application of distinct element method in dynamic analysis of high rock slopes and blocky structures, Soil Dynamics and Earthquake Engineering, 1997, 16(6): 385-394.

[11] E. Hoek, J. Read, A. Karzulovic, et al., Rock slopes in civil and mining engineering, In: International Conference on Geotechnical and Geological Engineering, Melbourne, 2000, 19-24.

[12] China Railway Eryuan Engineering Group Co. Ltd., The geological investigation report of Li-Xiang Railway, Chengdu, 2009.

[13] J.A.R. Ortigao, A.S.F.J. Sayao, Hand Book of Slope Stabilization, Germany: Springer, 2004.

[14] E. Hoek, Rock mechanics - the application of modern techniques to underground design, In: E. Hoek, ed., ourse note. Barazilian Rock Mechanics Committee, Barazilian Society for Soil Mechanics and Geotechnical
Engineering, Sao Paulo, Brazil, 1998.

[15] E. Hoek, Practical Rock Engineering, Netherlands: Balkema Publishers, 2000.

[16] N. Barton, The shear strength of rock and rock joints, Int. J. Rock Mech. Min. Sci. \& Geomech., 1976, 13: 1-24.

[17] N. Barton, V.D. Choubey, The shear strength of rock joints in theory and practice, Rock Mechanics, 1977, 10: $1-54$.

[18] D.U. Deere, R.P. Miller, Engineering classification and index properties of rock, Technical Report No. AFNLTR-65-116, Albuquerque, NM: Air Force Weapons Laboratory, 1966.

[19] GB/50330-2002, Technical code for building slope engineering (in Chinese).

[20] D. Kincaid, W. Cheney, Numerical Analysis: Mathematics of Scientific Computing, 3rd ed., Beijing: China Machine Press, 2003.

[21] Itasca Consulting Group: FLAC-Fast Lagrangian Analysis of Continua in 3 Dimensions, Version 2.00, User's Guide, Itasca Consulting Group Inc., USA, 1997.

[22] D.K. Keefer, Landslides caused by Earthquakes, Geological Sociaty of America Bulletin, 1984, 95: 406-421.

[23] L. Geli, P.Y. Bard, B. Jullien, The effects of topography on earthquake ground motion: a review and new results, Geol. Soc. Am. Bull., 1988, 78(1): 42-63.

[24] S. Ashford, N. Sitar, Simplified method for evaluating seismic stability of steep slopes, J. Geotech. Geoenviron., 2002, 128(2): 119-129.

[25] Itasca Consulting Group Inc., Universal Distinct Element Code User's Manual, Minneapolis, USA: Itasca Consulting Group Inc., 1999.

(Editor: Junsi LAN) 